\title{
Antihypertensive Drugs Prescribing Pattern in Patients Attending to Medicine Outpatient Department
}

\author{
Dr Akkamma Dadibhanvi MBBS (MD), Dr Padmaja Udaykumar MBBS(MD) \\ Department Of Pharmacology, Father Muller Medical College/ Rajiv Gandhi University of Health Science,
} Karnataka India

\begin{abstract}
Objective of study: To study the prescribing pattern of anti- hypertensive drugs in outpatient Medicine department.

Materials and Methods: A Cross sectional and observational study was carried out in Medicine outpatient department at Father Muller Medical College Hospital. Patients attending medicine department who have given their informed consent were included into the study. Detailed history, examination, relevant investigations and treatment received were recorded from the case record form and analysed. Collected data were analysed by frequency, percentage and chi-square test.

Result: A total 100 patients were analysed with mean age $63.1 \pm 13.5$ and $51 \%$ of Male. $78 \%$ of patient associated with type 2 Diabetes Mellitus. A total 227 prescriptions were analysed, among total prescription $53.7 \%$ of antihypertensive drugs. Among classes of antihypertensive $n=122(100 \%)$ most of patients were on $47.6 \%$ of Calcium channel Blockers (CCBs), $17.2 \%$ of Angiotensin II receptor blockers (ARBs) followed by $13 \%$ of Beta Blockers (BBs) and 10.6\% of Diuretics (DU). Among CCBs most common $n=45$ of amlodipine and other classes of antihypertensive $n=13$ of telmisartan(ARBs), $n=7$ of metoprolol (BBs)), Alpha Agonist like clonidine $(n=6)$ and furosemide $(n=6)$ were highest drugs used as monotherapy as well as combination of 2-3 antihypertensive groups. Patients also received atorvastatin and aspirin for other comorbid conditions.

Conclusion: Hypertension is chronic disorder and risk factor for cardiovascular disorder. Control of blood pressure will help to reduce the risk factors such as cardiovascular and cerebrovascular disorder specially strokes. In the present study patient were received maximally amlodipine, cilnidipine, telmisartan, furosemide and metoprolol.
\end{abstract}

\section{Introduction}

Hypertension is one of the most common non communicable diseases in the developing countries. It is one of risk factor for cardiovascular and cerebrovascular disorder. The present study was carried out to study the current trends in prescribing pattern of antihypertensive drugs. In India every $5^{\text {th }}$ person is having diabetes mellitus and hypertension is close association with diabetes prevalence of diabetes is predicted to rise from 171 million in 2000 to 366 million by 2030 and the number of adults with hypertension would increase by $60 \%$ to a total of 1.56 billion people by 2025 . $^{(1)}$ Hypertension increases the risk of diabetes related complications as well as micro and macro-vascular complications. Control of blood pressure indirectly may have a beneficial effect in reducing the incidence of complications. ${ }^{(2)}$

Objective of study:

To study the prescribing pattern of anti- hypertensive drugs in outpatient medicine department.

\section{Materials and Methods}

Study Design: A Cross sectional and observational study was carried out in Medicine outpatient department at Father Muller Medical College Hospital.

Method of Collection of Data:

Patients attending medicine department who have given their informed consent were included into the study. Detailed history, examination, relevant investigations and treatment received were recorded from the case record form and analysed.

Eligibility Criteria:

Inclusion Criteria:

Both male and female patients with age of above $18 \mathrm{yrs}$ with hypertension.

Exclusion Criteria:

- $\quad$ Patients admitted in ICU and ICCU

- Patients with acute renal failure.

- Patients with poor general condition like hemodynamic variations. 
Data analysis: Collected data were analysed by frequency, percentage and chi-square test.

Result: A total 100 patients were analysed with mean age $63.1 \pm 13.5$ and sex distribution was $51 \%$ of Male. Study populations were showed that $22 \%$ of pure hypertension and $78 \%$ of hypertension with type 2 diabetes mellitus (DM) and, associated cardiovascular co morbidities.

Mean Body Mass Index (BMI) of pt was 25.9 \pm 2.9 and mean Systolic Blood Pressure was $144.3 \pm 23.2$ and mean Diastolic Blood Pressure was $87.4 \pm 8.5$.

A total 227 prescriptions were analysed, 53.7\% of antihypertensive drugs and $46.2 \%$ of other than antihypertensive. All prescription was in trade name and average drug per patients in this study was 2.3.

Class of Antihypertensive drugs were received by patients is mentioned in (Vide Table-1).Among antihypertensive classes most common drugs $46.7 \%$ of Calcium Channel Blockers (CCBs), $17 \%$ of Angiotensin II receptor blockers (ARBs) ,13\% of Beta Blockers(BBs) patients were received. (Vide Figure-1) $63 \%$ of antihypertensive drugs were prescribed as monotherapy. (Vide Figure-2) Among single drug prescription $44 \%$ of amlodipine(CCBs), $4 \%$ of losartan and 3\% of atenolol were highest number of drugs received.(Vide Figure-3)

Most common drugs in combinations therapy were 5\% of CCBs+DU, $5 \%$ of $\mathrm{CCBs}+\mathrm{BBs}$ and followed by $3 \%$ ACE Inhibitors/ARBs +DU or BBs. (Vide Figure-4)

Non antihypertensive drugs $(\mathrm{n}=105)$ were received for hypertension associated co morbid conditions like Ischemic Heart Disease and dyslipidemia. Among non antihypertensives used in this study was $54 \%$ of hypolipidemic (Atorvastatin Maximum) and 50\% of antiplatelets (Aspirin Maximum). (Videfigure-5)

For the diabetes therapy patients were maximally on metformin alone or in combination with glimepiride antidiabetic drugs. Patients also had other co morbid conditions like thyroid disorder and urinary tract infections.

\begin{tabular}{|l|l|}
\hline Classes of Antihypertensive Drugs & $\begin{array}{l}\text { Frequency and Percentage } \\
(\mathbf{n}=122 \text { \& 100\%) }\end{array}$ \\
\hline Calcium Channel Blockers(CCBs) & $\mathbf{5 8 ( 4 6 . 7 \% )}$ \\
\hline Amlodipine & 45 \\
\hline Cilnidipine & 7 \\
\hline Diltiazem & 3 \\
\hline Nicardipine & 2 \\
\hline Nifedipine & 1 \\
\hline Beta Blockers(BBs) & $\mathbf{1 6 ( 1 3 . 1 \% )}$ \\
\hline Atenolol & 5 \\
\hline Metoprolol & 7 \\
\hline Propranalol & 2 \\
\hline Nebivolol & 1 \\
\hline Bisoprolol & 1 \\
\hline Alpha 2-Agonists & $\mathbf{6 ( 4 . 9 \% )}$ \\
\hline Clonidine & 6 \\
\hline Angiotensin converting enzyme (ACE) inhibitors & $\mathbf{9 ( 7 . 3 \% )}$ \\
\hline Ramipril & 5 \\
\hline Enalapril & 4 \\
\hline Angiotensin II receptor blockers (ARBs) & $\mathbf{2 1 ( 1 7 . 2 \% )}$ \\
\hline Losartan & 8 \\
\hline Telmisartan & 13 \\
\hline Diuretics(DU) & $\mathbf{1 3 ( 1 0 . 6 \% )}$ \\
\hline Chlorthalidone & 5 \\
\hline Furosemide & 6 \\
\hline Torsemide & 2 \\
\hline
\end{tabular}

Table 1: Common Class of Antihypertensive Drugs 


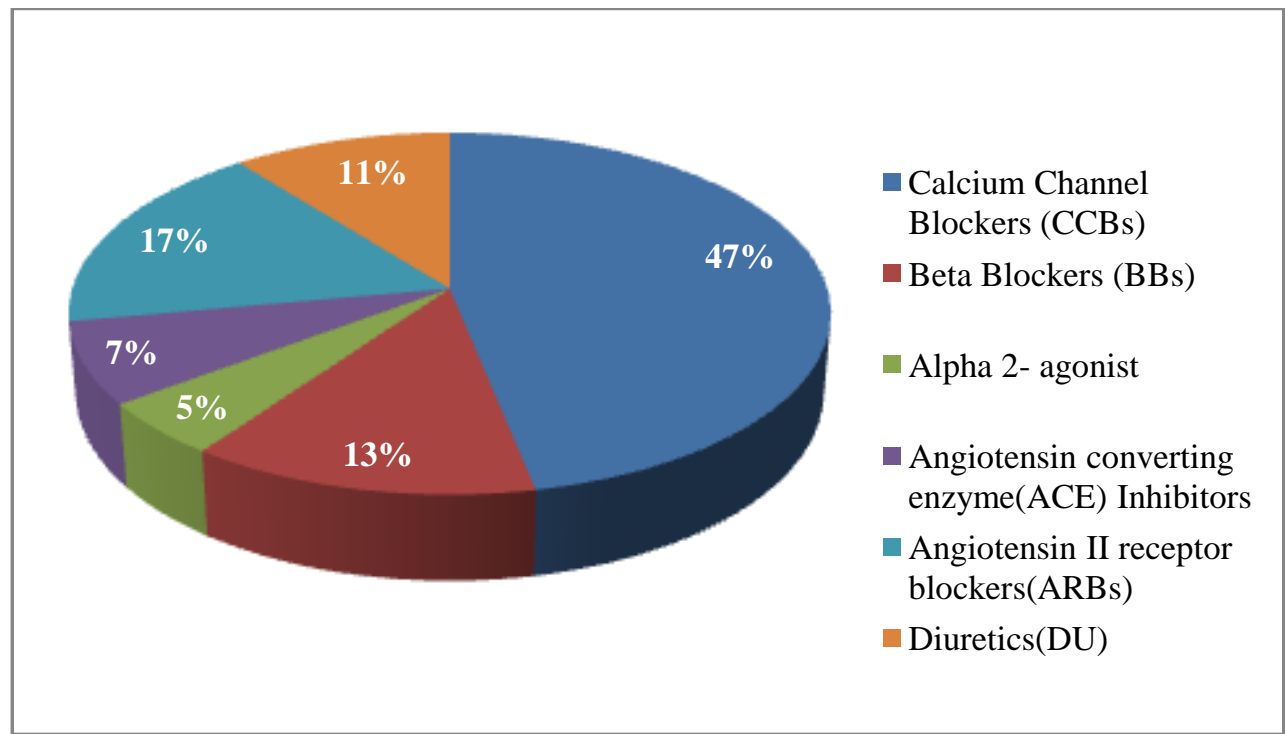

Figure 1: Frequency of Classes of Antihypertensive

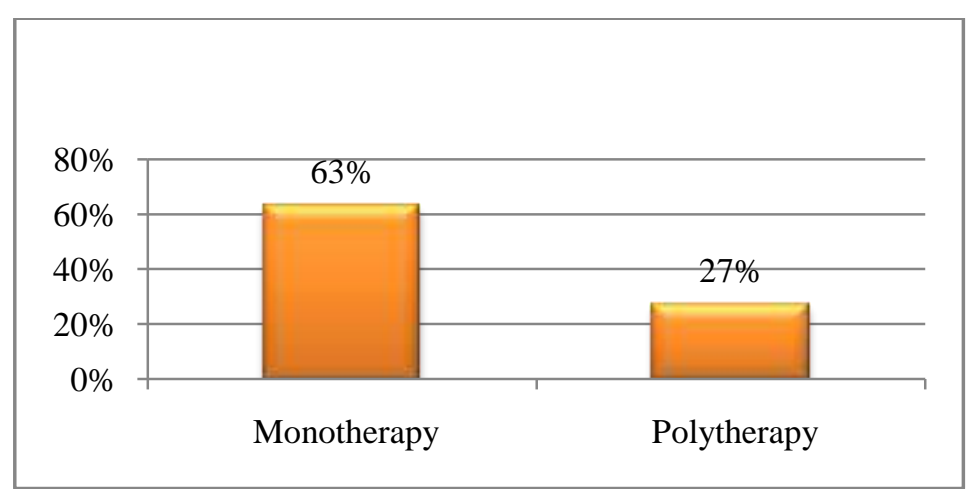

Figure 2: Frequency of Type of Prescription of Antihypertensive drugs

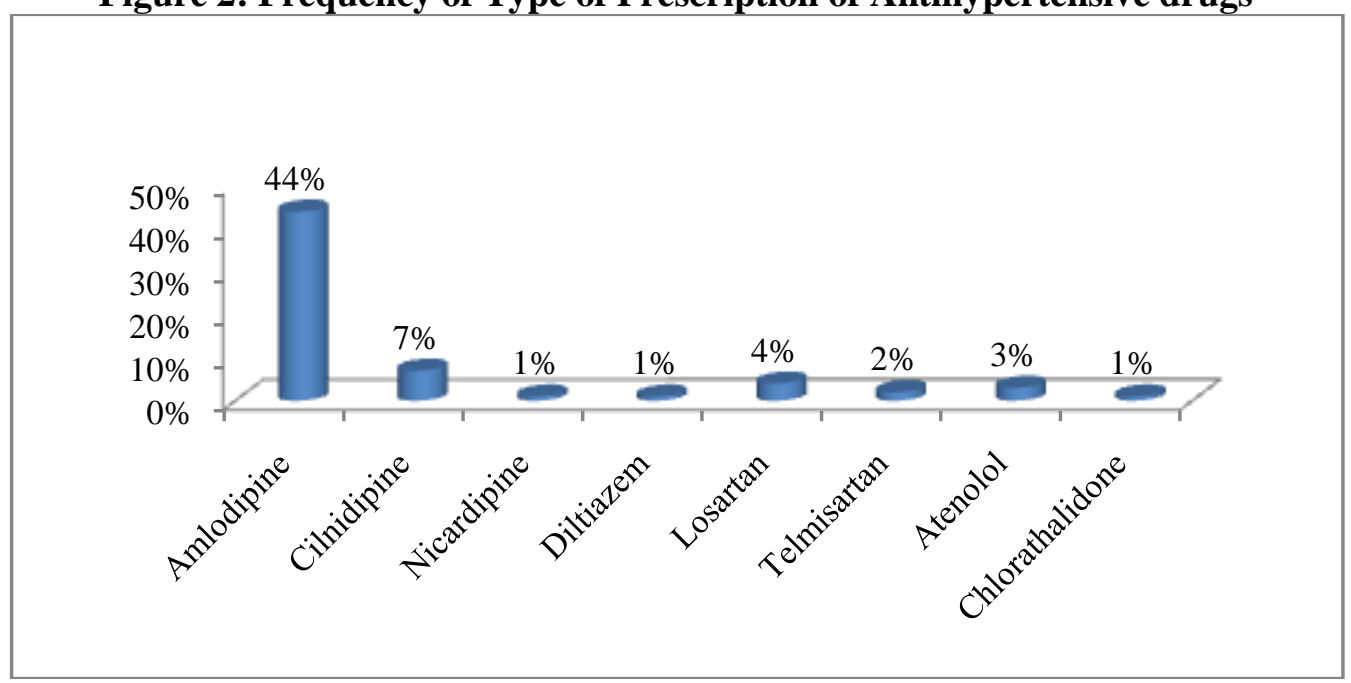

Figure 3: Frequency of Antihypertensive Drugs prescribed as Monotherapy 


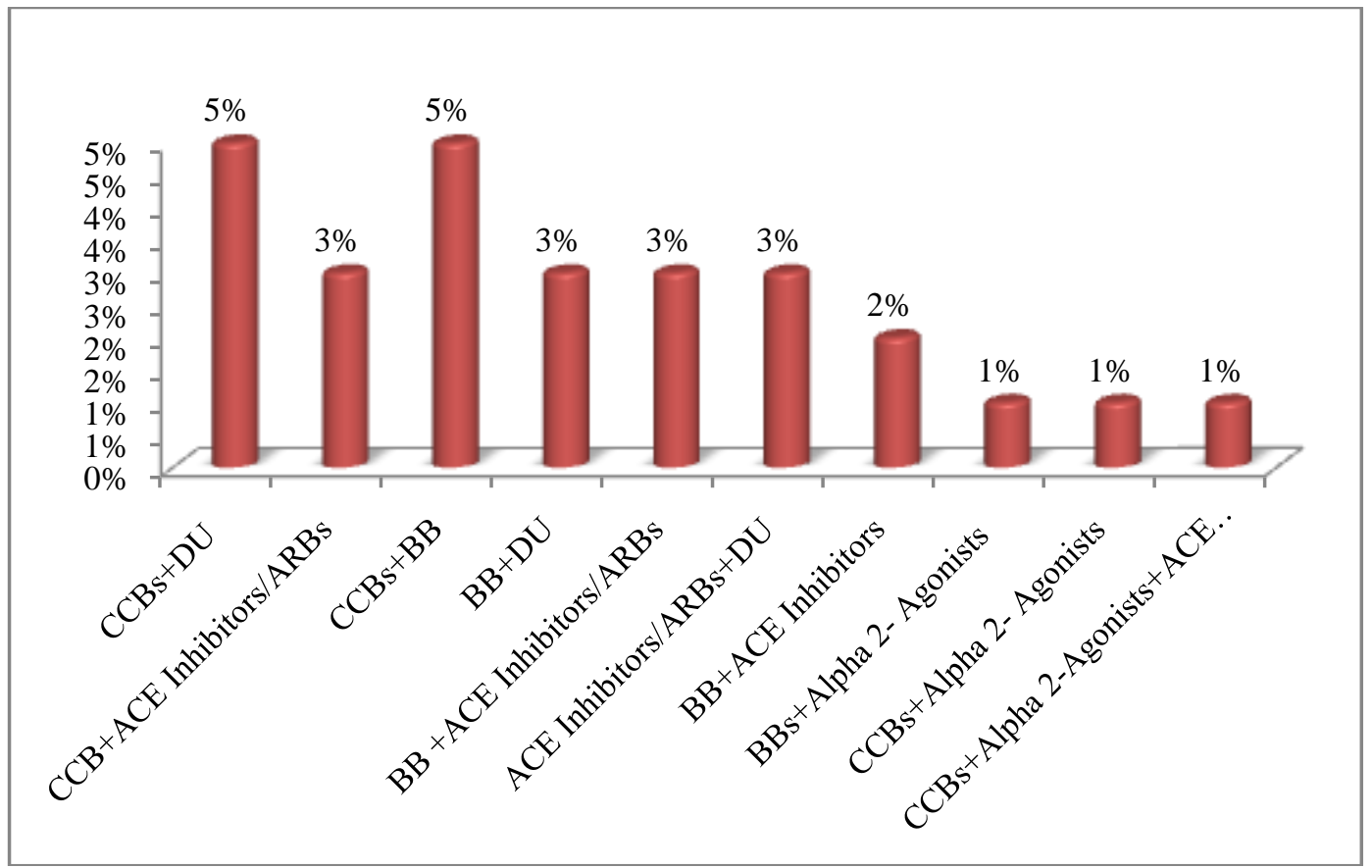

Figure 4: Frequency of combinations of classes of Antihypertensive Drugs

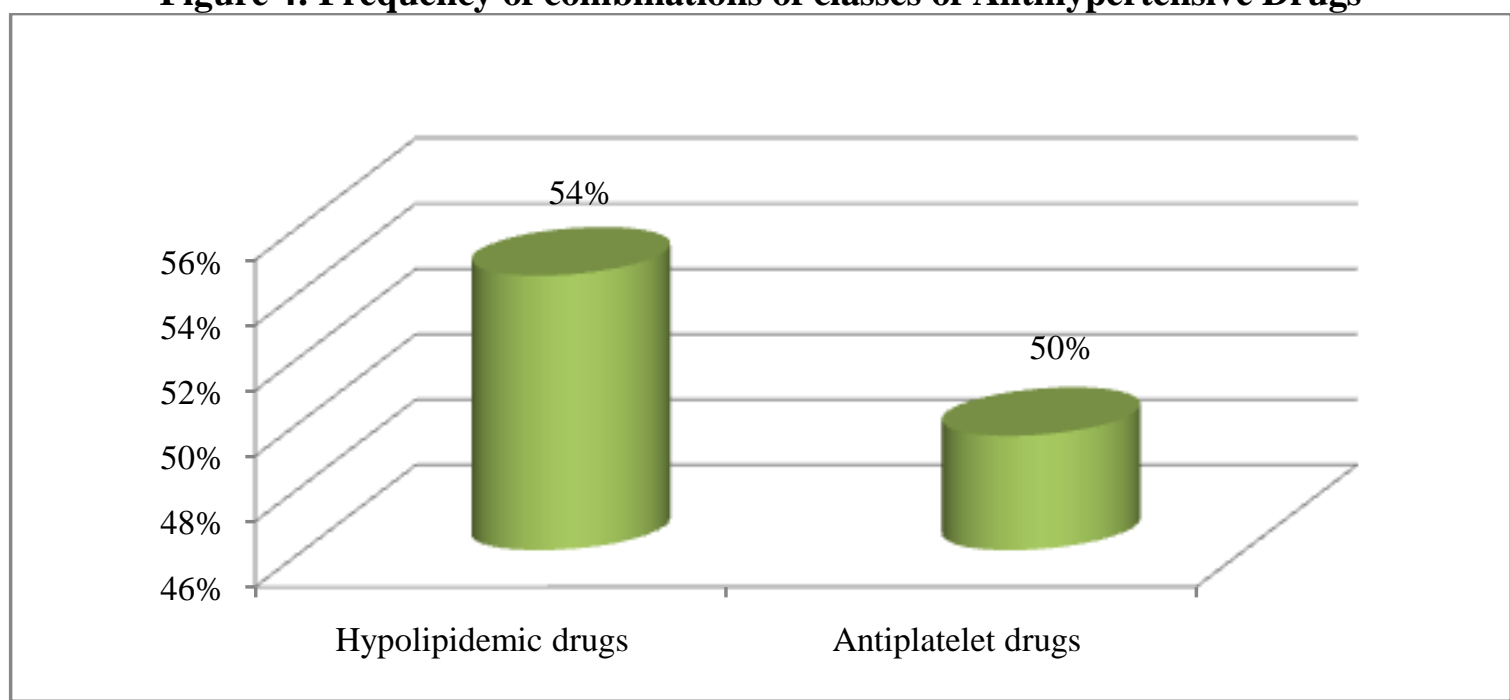

Figure 5: Frequency of drugs for co morbid conditions

\section{Discussion}

Our study reviewed that most of patients were on Calcium Channel Blockers (CCBs), Angiotensin II receptor blockers (ARBs) and Diuretics (DU). All antihypertensive Drugs were in trade name and an average drug per patients was 2.3.A study conducted by Singh P et al observed that most of patients were on Calcium channel blockers (CCBs)- Amlodipine followed by Angiotensin-converting-enzyme inhibitors- Enalapril and $\beta$ blockers-Atenolol. ${ }^{(3)}$ Most common drugs used were calcium channel blockers (CCBs) and Beta blockers(BBs) in the study done by Rathod P S et al and he stated that CCBs and BBs were better tolerated and had better antihypertensive efficacy. ${ }^{(4)}$ In the monotherapy (63\%), highest drugs $44 \%$ of amlodipine(CCBs), $4 \%$ of losartan and 3\% of atenolol were received as single drug in both cases pure hypertension and associated co morbid conditions. Out of 93 prescription $53.76 \%$ were prescribed with monotherapy in the study done by Philip R et al and he also revealed that in pure hypertensive cases as monotherapy highest drugs $62 \%$ of amlodipine, $22 \%$ of telmisartan, atenolol (4\%), metoprolol (2\%) and carvedilol (2\%) were received. ${ }^{(5)}$ In this study most of hypertensive patient associated with diabetes were on CCBs alone or in combination with diuretics, beta blockers or ACE inhibitors/ARBs. Similarlly study done by Johnson M L et al showed that most common drugs ACE Inhibitors /ARBs or alpha blockers were received in hypertension associated with diabetes.$^{(6)}$ 


\section{Conclusion}

Hypertension is chronic disorder and it is the one of the risk factor for cardiovascular disorder. Control of blood pressure will help to reduce the risk factors for cardiovascular and cerebrovascular disorder. In this study most of patients were hypertension associated with co morbid condition and treatment is very important for in these cases and rational of drug prescription. Feature studies are required to evaluate of antihypertensive drugs prescription according standard guidelines. In our study most of patients were on maximally on amlodipine, telmisartan, furosemide and metoprolol as antihypertensive drugs.

\section{References}

[1]. Swami SS, Swami SC, Patil VW, Kanhere AM. HYPERTENSION AND DIABETES IN INDIA: A REVIEW. Int J Clin Biochem Res. 2(1):54-8.

[2]. Dhanaraj E, Raval A, Yadav R, Bhansali A, Tiwari P. Prescription Pattern of Antihypertensive Agents in T2DM Patients Visiting Tertiary Care Centre in North India. Int J Hypertens [Internet]. 2012 [cited 2016 Aug 31];2012:520915. Available from: http://www.ncbi.nlm.nih.gov/pubmed/23316345

[3]. Singh P, Singh K, Shrivastava R, Pandey V, Singh A, Raj B. Frequency, Preferences and Prescribing Pattern of Antihypertensive Drugs in Out-Patient Department of a Tertiary Care SGM Hospital, Rewa District of Madhya Pradesh, India. Indian Pract. 2016;69(3):32-9

[4]. Rathod DPS, Patil DPT. Current Trends in Prescription Pattern of Antihypertensive Drugs in indoor Hypertensive Patients in A Tertiary Care Hospital Attached to A Government Medical College of Maharashtra: A Retrospective Study. Glob J Res Anal. 2016;5(6).

[5]. Philip R, A. DK, Mathew M, Reddy VLT, M. MN, Krishnamurthy MS. Prescribing patterns of antihypertensive drugs in geriatric population in tertiary care hospital. Int J Pharmacol Res. 2016;6(3):114-9.

[6]. Johnson ML, Singh H. Patterns of antihypertensive therapy among patients with diabetes. J Gen Intern Med [Internet]. 2005 Sep [cited 2016 Aug 31];20(9):842-6. Available from: http://www.ncbi.nlm.nih.gov/pubmed/16117753 